\title{
ARTICLE
}

\section{Assessment of genetic diversity in sea buckthorn (Hippophae rhamnoides L.) accessions from Mongolia based on RAPD markers}

\author{
Zolzaya Sandag ${ }^{\# 1}$, Dorjderem Balchin ${ }^{\# 2}$, Ariya Enkhtuya ${ }^{\# 1}$, Nomin Myagmar $^{1}$, Nomuun Oyunbat ${ }^{1}$ \\ Khurelsukh Buyanbat ${ }^{1}$, Sosorburam Batnasan ${ }^{1}$, Ninj Badam ${ }^{3}$, Jamiyansuren Sandagdorj ${ }^{4}$ \\ Oyunsuren Tsendsuren ${ }^{1}$ and Gantulga Davaakhuu ${ }^{1 *}$ \\ ${ }^{1}$ Laboratory of Molecular Biology, Institute of Biology, \\ Mongolian Academy of Sciences, Ulaanbaatar, Mongolia. \\ ${ }^{2}$ laboratory of Plant introduction and genetic resources, Botanical Garden and Research Institute, \\ Mongolian Academy of Sciences, Ulaanbaatar, Mongolia. \\ ${ }^{3}$ School of Agroecology, Mongolian University of Life Sciences, Ulaanbaatar, Mongolia. \\ ${ }^{4}$ National Forest Corporation LS, Ulaanbaatar, Mongolia. \\ \# These authors contributed equally to this work.
}

Abstract: Hippophae rhamnoides L., which belongs to the Elaegnaceae family, is one of the medically and environmentally valuable berry crops with its high nutritious and bioactive compounds. Despite its high demand in the food, medicinal and agricultural industries, this species has been less studied molecularly. In view of this, an effort has been made in the present study to characterize 24 accessions of $H$. rhamnoides collected from different geographical regions of Mongolia through random amplified polymorphic DNA (RAPD) markers. A total of 10 RAPD primers were used in the present study for their ability to produce clear, scorable amplicons. The RAPD analysis totally generated 87 bands, of which 84 (96.34\%) were polymorphic, pointing to a high degree of genetic variation. The similarity coefficient ranged from 0.4-1 with the mean of 0.78. The UPGMA dendrogram was generated using these data grouped accessions into two main clusters. Cluster analysis reflected a relatively close relationship between accessions grown at the same or neighbouring areas. Thus, our data could be informative for further selection and management of germplasm collections and crossing strategies for sea buckthorn.

Keywords: Hippophae rhamnoides L.; genetic distance; RAPD; UPGMA dendrogram; Dice similarity coefficient;

\section{INTRODUCTION}

Sea buckthorn (Hippophae rhamnoides L.) is a dioecious and multipurpose plant, belonging to the Elaegnaceae [1] family. Sea buckthorn is known for its tolerance of growing extreme conditions, such as temperatures ranging from -40 to $40^{\circ} \mathrm{C}$, droughts, and high altitudes [2]. These diverse growing conditions are essential for its genetic diversity.

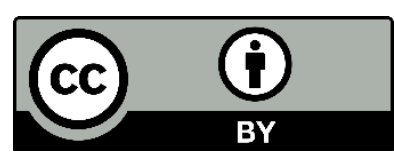

The Author(s). 2021 Open access This article is distributed under the terms of the Creative Commons Attribution 4.0 International License (https://creativecommons.org/licenses/by/4.0/), which permits unrestricted use, distribution, and reproduction in any medium, provided you give appropriate credit to the original author(s) and the source, provide a link to the Creative Commons license, and indicate if changes were made. 
According to the latest classification, four subspecies of $H$. rhamnoides L. are distributed across Asia (subsp. mongolica, turkestanica, sinensis and yunnanesis), in Europe (subs. rhamnoides, fluviatilis and carpatica) and in Asia Minor (subsp. caucasica) [3], [4]. This wind-pollinated woody plant is widely distributed across Asia and Europe with distribution ranging from seashores to mountainous terrain [5]. Mongolia has a broad range of natural production of sea buckthorn covering $29,000 \mathrm{~km}^{2}$ (data only available for Uvs aimag - province), China's natural production range covers more than $10,000 \mathrm{~km}^{2}$, while former USSR covers $472 \mathrm{~km}^{2}$ [6]-[8].

This plant attracts very high medicinal interest due to its therapeutic potential and a range of pharmacological applications, such as for cardiovascular diseases, cancer, obesity, diabetes, ulcers, inflammations, immune system diseases, burn wounds, and radiation damage [9], [10].

Various important bioactive substances have been reported for $H$. rhamnoides L. plant including vitamins, mineral elements, alkaloids, flavonoids, carotenoids, phytosterols, tannins, triterpenoids, phospholipids, catechins, coumarin, fatty acids and unsaturated fatty acids [11]-[13].

In the last few decades, sea buckthorn has been admired not only for its medicinal

\section{MATERIALS AND METHODS}

\section{Plant material}

A total of $24 \mathrm{H}$. rhamnoides L. samples (seeds) were collected from different geographical regions of Mongolia. Samples were collected between 2015 and 2019 from properties, but also for its ecological and commercial value. It is traditionally processed into juice, jam, alcoholic drinks, oil, and cosmetic products [6]. It too has a high potential for preventing soil erosion and soil water loss, contributing to ecological stability [8].

There are various methods for assessing the genetic diversity of the plant species. It can be analyzed either using morphological methods or molecular markers. However, phenotypic characters are affected by environmental factors, with some limited usage. Molecular markers have proven to be a powerful tool for assessing genetic variation and interpreting genetic relationship within and among the species [14]. Random amplified polymorphic DNA (RAPD) has been extensively used for determining genetic relationship among germplasm collection, genetic diversity of $H$. rhamnoides L. [15]-[17].

As per our knowledge and literature survey, there is a lack of information on the molecular characterization of $H$. rhamnoides $\mathrm{L}$. plant in Mongolia. And so the present study was carried out with different accessions of $H$. rhamnoides L. collected from various geographical regions of Mongolia using RAPD markers. Our data provides the scientific basis for future selection and management of germplasm.

Table 1. Details of $\mathrm{H}$. rhamnoides accession collected from different regions of Mongolia for genetic diversity analysis

\begin{tabular}{cllcc}
\hline \multirow{2}{*}{ S. no } & \multicolumn{1}{c}{ Accession name } & \multicolumn{1}{c}{ Place of collection } & $\begin{array}{c}\text { Accession } \\
\text { type }\end{array}$ & Date \\
\hline 1 & Aldarkhaan & Zavkhan aimag, Aldarkhaan soum & $\mathrm{W}$ & 2015 \\
2 & Chuiskaya & Uvurkhangai aimag, Kharkhorin soum & $\mathrm{C}$ & 2019 \\
3 & Zavkhan Tes & Zavkhan aimag, Tes soum & $\mathrm{W}$ & 2019 \\
4 & Khar but 8 & Zavkhan aimag, Dorvoljin soum & $\mathrm{W}$ & 2019 \\
5 & Khar but 4 & Zavkhan aimag, Dorvoljin soum & $\mathrm{W}$ & 2019 \\
6 & Khar but 2 & Zavkhan aimag, Dorvoljin soum & $\mathrm{W}$ & 2019 \\
7 & Jirmiin burgas & Zavkhan aimag, Dorvoljin soum & $\mathrm{W}$ & 2019 \\
8 & Khovd Erdene buren & Khovd aimag, Erdene buren soum & $\mathrm{W}$ & 2019 \\
9 & Bokhmoron & Uvs aimag, Bokhmoron soum & $\mathrm{W}$ & 2015
\end{tabular}




\begin{tabular}{|c|c|c|c|c|}
\hline 10 & Uvs Tes Toormt & Uvs aimag, Tes soum & $\mathrm{W}$ & 2015 \\
\hline 11 & Aldarkhaan Borkh 2 & Zavkhan aimag, Aldarkhaan soum & W & 2019 \\
\hline 12 & Khovd Bulgan & Khovd aimag, Bulgan soum & $\mathrm{W}$ & 2019 \\
\hline 13 & Selenge Buduunii guur & Selenge aimag, Zuunburen soum & $\mathrm{W}$ & 2015 \\
\hline 14 & Uvs Turgen & Uvs aimag, Turgen soum & $\mathrm{W}$ & 2015 \\
\hline 15 & Uvs Tes 1 & Uvs aimag, Tes soum 1 & W & 2014 \\
\hline 16 & Uvs Tes 2 & Uvs aimag, Tes soum 2 & $\mathrm{~W}$ & 2014 \\
\hline 17 & Khovd Bulgan & Khovd aimag, Bulgan soum & $\mathrm{W}$ & 2019 \\
\hline 18 & Selenge wangiin tohoi & Selenge aimag, zuunburen soum & $\mathrm{W}$ & 2015 \\
\hline 19 & Khar but & Zavkhan aimag, Dorvoljin soum & $\mathrm{W}$ & 2015 \\
\hline 20 & Khovd Bulgan 2015 & Khovd aimag, Bulgan soum & $\mathrm{W}$ & 2015 \\
\hline 21 & Aldarkhaan 4 & Zavkhan aimag, Aldarkhaan soum & $\mathrm{W}$ & 2019 \\
\hline 22 & Zavkhan Tes 2015 & Zavkhan aimag, Tes soum & $\mathrm{W}$ & 2015 \\
\hline 23 & Khovd Bulgan 2 & Khovd aimag, Bulgan soum & $\mathrm{W}$ & 2019 \\
\hline 24 & Bayan-Olgii & Bayan-Olgii aimag, Altantsogts soum & W & 2019 \\
\hline
\end{tabular}

\section{DNA extraction}

DNA was extracted from each seed sample. Samples were placed in a mortar with liquid nitrogen and ground to fine powder and transferred to a $1.5 \mathrm{ml}$ microcentrifuge tube. 1 $\mathrm{ml}$ extraction buffer $(250 \mathrm{mM} \mathrm{NaCl}, 25 \mathrm{mM}$ EDTA, 0.5\% SDS, $200 \mathrm{mM}$ Tris- $\mathrm{HCl} \mathrm{pH} 8.0$ ) was added into the tube. The mix was incubated at $65^{\circ} \mathrm{C}$ for $1 \mathrm{hr} 30 \mathrm{~min}$, vortexed every $30 \mathrm{~min}$. $60 \mathrm{mg}$ Polyvinylpyrrolidone (PVP), $500 \mu \mathrm{l} 7.5$ $\mathrm{M}$ ammonium acetate were added, and incubated on ice for $30 \mathrm{~min}$. The tube was centrifuged at $13000 \mathrm{rpm}$ for $10 \mathrm{~min}$ at $4^{\circ} \mathrm{C}$, supernatant was transferred into a clear tube. Same amount of isopropanol was added and incubated in $-20^{\circ} \mathrm{C}$ for $30 \mathrm{~min}$. The mix was centrifuged in $13000 \mathrm{rpm}$ in $4^{\circ} \mathrm{C}$ for $20 \mathrm{~min}$, and supernatant was removed. The resulting DNA pellet was washed with $1 \mathrm{ml}$ of $70 \%$ ethanol, and then resuspended in RNAse/DNAse free water [18]. The purity and concentration of DNA samples were assessed by Nanodrop 2000/2000c and 1\% agarose gel electrophoresis.

\section{RAPD analysis}

RAPD profiles were generated by using 10 polymorphic 10-mers (Table2). PCR amplification reagents were carried out in $20 \mu \mathrm{l}$ final volume of reaction mixture containing Dream Taq buffer $\left(2 \mathrm{mM} \mathrm{MgCl}_{2}\right), 0.2 \mathrm{mM}$ of dNTP, $0.2 \mu \mathrm{M}$ of primer (Macrogen), $1.5 \mathrm{U}$ DreamTaq DNA Polymerase (Thermo Fisher Scientific), and $50 \mathrm{ng}$ of genomic DNA. A PCR thermocycler (Applied Biosystems 2720) was used with the following program: an initial step of $3 \mathrm{~min}$ at $94^{\circ} \mathrm{C} 3 \mathrm{~min}$, followed by 45 cycles of $45 \mathrm{sec}$ at $94^{\circ} \mathrm{C}, 45 \mathrm{sec}$ at $36^{\circ} \mathrm{C}$, and $1 \mathrm{~min} 30$ sec at $72^{\circ} \mathrm{C}$, and a final extension step of $7 \mathrm{~min}$ at $72^{\circ} \mathrm{C}$. The PCR products were separated on $1.5 \%$ agarose gels, stained with ethidium bromide, and visualized under UVtransillumination after ethidium bromide staining.

Table 2. The nucleotide sequences and melting temperatures of the ten selected primers

\begin{tabular}{lll}
\hline Primer & \multicolumn{1}{c}{ Primer sequence $\left(5^{\prime}-3^{\prime}\right)$} & Melting temp. $\left({ }^{\circ} \mathrm{C}\right)$ \\
\hline OPA-07 & GAAACGGGTG & 32.0 \\
OPA-08 & GTGACGTAGG & 32.0 \\
OPD-03 & GTCGCCGTCA & 34.0 \\
OPD-16 & AGGGCGTAAG & 32.0 \\
OPA-02 & TGCCGAGCTG & 34.0 \\
OPA-11 & CAATCGCCGT & 32.0 \\
OPC-15 & GACGGATCAG & 32.0 \\
OPD-05 & TGAGCGGACA & 32.0 \\
OPD-15 & CATCCGTGCT & 32.0 \\
OPD-18 & GAGAGCCAAC & 32.0 \\
\hline
\end{tabular}


Data analysis

In this study, RAPD bands were scored as present (1) and absent (0) and a binary matrix was computed; only clear and distinct bands were included in the analysis. Genetic distance and similarity were determined by Dice's coefficient of similarity. Dice's coefficient of similarity presented as percentage was calculated pairwise comparisons between individual samples according the formula:

$$
\text { Dice }\left(P_{i}, P_{j}\right) D \equiv \frac{2 \times n_{i j}}{n_{i}+n_{j}}
$$

\section{RESULTS AND DISCUSSION}

\section{RAPD marker analysis}

Known for thier reliability and simplicity, the RAPD markers were used. A genetic diversity study among the 24 accessions of $H$. rhamnoides L. was carried out using a total of 10 random decamer oligonucleotide primers to investigate the ability of amplification of genomic DNA. From among them, 8 primers (OPA-07; OPA-08; OPD-03; OPD-16; OPA02; OPA-11; OPD-15; OPD-18) that successfully produced clear amplicons, were selected for our further study (Fig.1; Table 3). According to RAPD analysis, out of total of 87 bands 84 (96.34\%) bands were polymorphic, whereas $3(3.66 \%)$ were monomorphic. The number of bands per primer ranged from 4 to where:

$n_{i j}$ is common band number between samples $P_{i}$ and $P_{j}$

$n_{i}$ band number for sample $P_{j}$

Based on this similarity coefficient, the genetic distance was calculated and an UPGMA dendrogram was constructed. In order to construct the dendrogram, primers were chosen containing at least one monomorphic band and most polymorphic band pattern.

16. On an average, 10.87 bands per primer were seen. Taken together, our data showed that the highest polymorphism was detected by OPA-11 primer, while the lowest polymorphism was detected by the OPD-03 primer. Previously, various studies have explored the genetic relationship and diversity of sea buckthorn either in the same species or different species. Jeppsson et al. reported that native sea buckthorn populations of Northern Europe from the Netherlands to Sweden revealed 85\% variation [19]. Bartish et al. revealed that after RAPD analysis on $55 \mathrm{H}$. rhamnoides $\mathrm{L}$. cultivars and accession of gene bank in Sweden showed $86.3 \%$ polymorphism, which is a sign of high diversity [20].

Table 3. Number of amplification products generated with random oligonucleotide primers for 24 accessions

\begin{tabular}{lccc}
\hline Primer & $\begin{array}{c}\text { Total number of RAPD } \\
\text { products per primer }\end{array}$ & $\begin{array}{c}\text { Total number of polymorphic } \\
\text { RAPD products }\end{array}$ & Sequence of primers \\
\hline OPA-07 & 12 & 12 & 5'-GAAACGGGTG-3' \\
OPA-08 & 10 & 10 & 5'-GTGACGTAGG-3' \\
OPD-03 & 4 & 4 & 5'-GTCGCCGTCA-3' \\
OPD-16 & 9 & 8 & 5'-AGGGCGTAAG-3' \\
OPA-02 & 11 & 9 & 5'-TGCCGAGCTG-3' \\
OPA-11 & 16 & 16 & 5'-CAATCGCCGT-3' \\
OPD-15 & 13 & 13 & 5'-CATCCGTGCT-3' \\
OPD-18 & 12 & 12 & 5'-GAGAGCCAAC-3' \\
Total & & & \\
Total \% & 87 & 84 & \\
\hline
\end{tabular}




\section{$\begin{array}{lllllllllllllllllllllllll}1 & 2 & 3 & 4 & 5 & 6 & 7 & 8 & 9 & 10 & 11 & 12 & 13 & 14 & 15 & 16 & 17 & 18 & 19 & 20 & 21 & 22 & 23 & 24 & M\end{array}$}

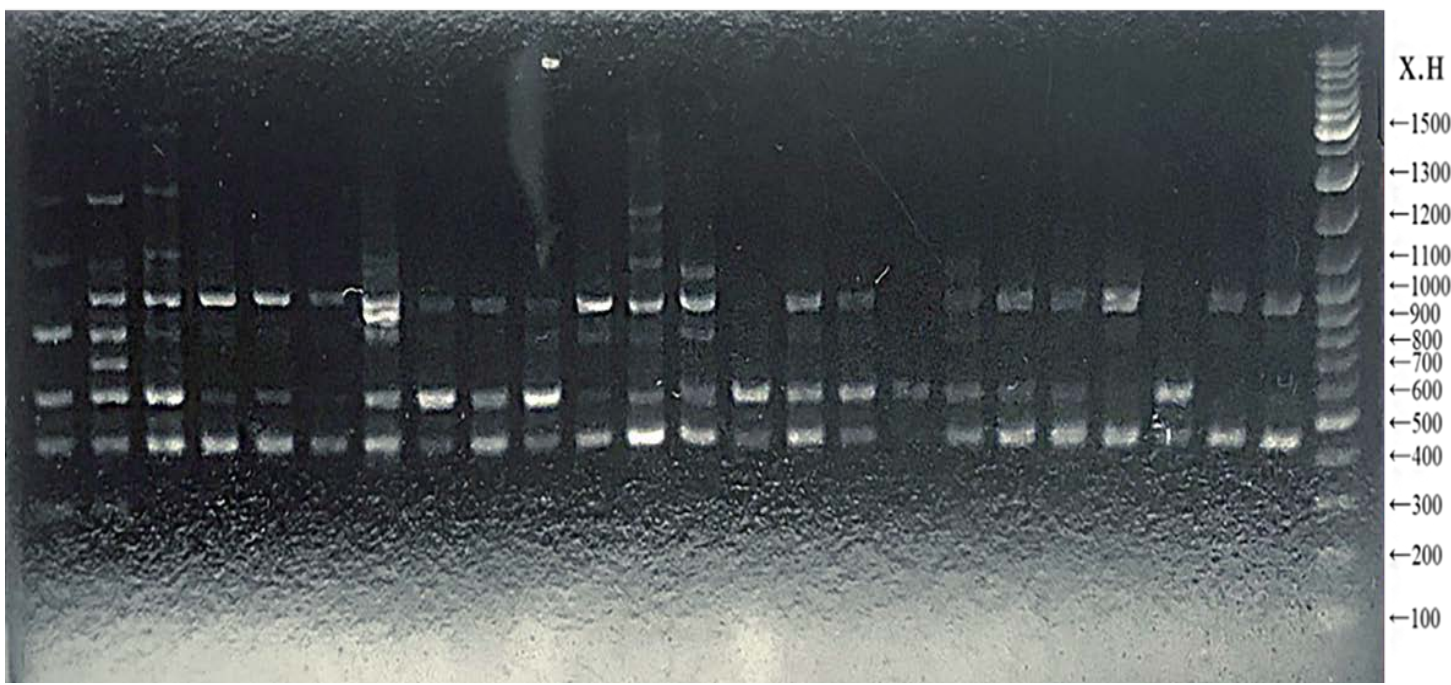

Figure 1. RAPD patterns amplified with primer OPA-08 H. rhamnoides. M indicates the size standard (Generuler 1kb Plus DNA Ladder, Thermo Fisher) Plus DNA Ladder, Thermo Fisher)

RAPD-based cluster analysis

Based on RAPD analysis, OPA-02 primer showed high degree of polymorphism and contained at least one monomorphic band, and so OPA-02 was chosen for further analysis (Figure 2). The Dice similarity coefficient was computed and the obtained values per OPA-02 primer were compared. Matrix analysis of RAPD data revealed that Dice's similarity coefficient is in the range of $0.4-1$, with a mean of 0.78 (Table 4 ). This reflected the presence of a high genetic variability among accessions under study.

\section{$\begin{array}{lllllllllllllllllllllllll}\mathrm{M} & 1 & 2 & 3 & 4 & 5 & 6 & 7 & 8 & 9 & 10 & 11 & 12 & 13 & 14 & 15 & 16 & 17 & 18 & 19 & 20 & 21 & 22 & 23 & 24\end{array}$}

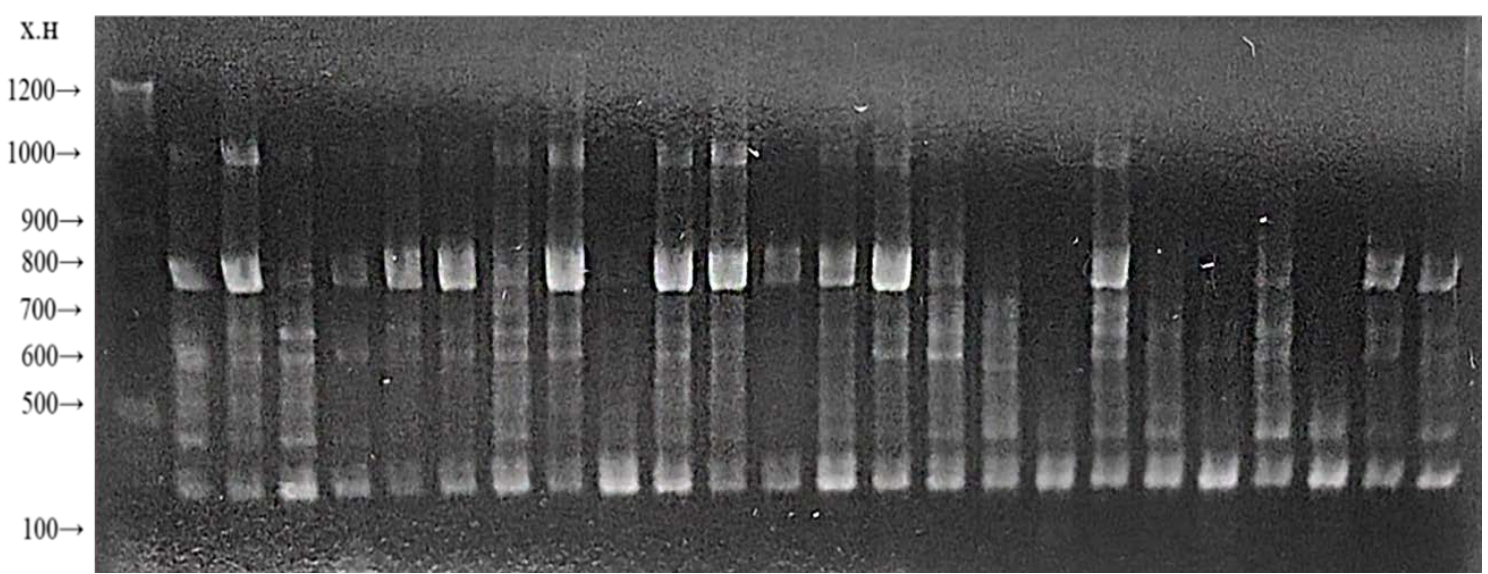

Figure 2. RAPD patterns amplified with primer OPA-02 H. rhamnoides 
Table 4. Dice's similarity coefficient based on RAPD analysis in $24 \mathrm{H}$. rhamnoides accessions according primer OPA-02 (\%)

\begin{tabular}{|c|c|c|c|c|c|c|c|c|c|c|c|c|c|c|c|c|c|c|c|c|c|c|c|c|}
\hline Population & 1 & 2 & 3 & 4 & 5 & 6 & 7 & 8 & 9 & 10 & 11 & 12 & 13 & 14 & 15 & 16 & 17 & 18 & 19 & 20 & 21 & 22 & 23 & 24 \\
\hline 1 & - & & & & & & & & & & & & & & & & & & & & & & & \\
\hline 2 & 1 & - & & & & & & & & & & & & & & & & & & & & & & \\
\hline 3 & 0.95 & 0.95 & - & & & & & & & & & & & & & & & & & & & & & \\
\hline 4 & 0.88 & 0.88 & 0.82 & - & & & & & & & & & & & & & & & & & & & & \\
\hline 5 & 0.88 & 0.88 & 0.82 & 1 & - & & & & & & & & & & & & & & & & & & & \\
\hline 6 & 0.88 & 0.88 & 0.82 & 1 & 1 & - & & & & & & & & & & & & & & & & & & \\
\hline 7 & 0.89 & 0.89 & 0.95 & 0.88 & 0.88 & 0.88 & - & & & & & & & & & & & & & & & & & \\
\hline 8 & 0.94 & 0.94 & 0.89 & 0.93 & 0.93 & 0.93 & 0.94 & - & & & & & & & & & & & & & & & & \\
\hline 9 & 0.5 & 0.5 & 0.46 & 0.4 & 0.4 & 0.4 & 0.5 & 0.55 & - & & & & & & & & & & & & & & & \\
\hline 10 & 0.94 & 0.94 & 0.89 & 0.93 & 0.93 & 0.93 & 0.94 & \begin{tabular}{l|l}
1 & ( \\
\end{tabular} & 0.55 & - & & & & & & & & & & & & & & \\
\hline 11 & 0.94 & 0.94 & 0.89 & 0.93 & 0.93 & 0.93 & 0.94 & 1 & 0.55 & 1 & - & & & & & & & & & & & & & \\
\hline 12 & 0.8 & 0.8 & 0.75 & 0.92 & 0.92 & 0.92 & \begin{tabular}{|l|}
0.8 \\
\end{tabular} & \begin{tabular}{|l|l}
0.86 \\
\end{tabular} & 0.44 & 0.86 & 0.86 & - & & & & & & & & & & & & \\
\hline 13 & 0.94 & 0.94 & 0.89 & 0.93 & 0.93 & 0.93 & 0.94 & \begin{tabular}{|l|l}
1 & ( \\
\end{tabular} & 0.55 & 1 & 1 & 0.86 & - & & & & & & & & & & & \\
\hline 14 & 0.94 & 0.94 & 0.89 & 0.93 & 0.93 & 0.93 & 0.94 & 1 & 0.55 & 1 & 1 & 0.86 & 1 & - & & & & & & & & & & \\
\hline 15 & 0.94 & 0.94 & 0.89 & 0.93 & 0.93 & 0.93 & 0.94 & 1 & 0.55 & 1 & 1 & 0.86 & 1 & 1 & - & & & & & & & & & \\
\hline 16 & 0.71 & 0.71 & 0.67 & 0.67 & 0.67 & 0.67 & 0.71 & \begin{tabular}{|l|l}
0.77 \\
\end{tabular} & 0.75 & 0.77 & 0.77 & 0.73 & 0.77 & 0.77 & \begin{tabular}{|l|}
0.77 \\
\end{tabular} & - & & & & & & & & \\
\hline 17 & 0.5 & 0.5 & 0.46 & 0.4 & 0.4 & 0.4 & 0.5 & \begin{tabular}{|l|l|}
0.55 \\
\end{tabular} & 1 & 0.55 & 0.55 & 0.44 & 0.55 & 0.55 & 0.55 & 0.75 & - & & & & & & & \\
\hline 18 & 0.9 & 0.9 & 0.95 & 0.78 & 0.78 & 0.78 & \begin{tabular}{|l|}
0.9 \\
\end{tabular} & \begin{tabular}{|l|l}
0.84 \\
\end{tabular} & 0.43 & 0.84 & 0.84 & 0.71 & 0.84 & 0.84 & 0.84 & 0.63 & 0.43 & - & & & & & & \\
\hline 19 & 0.67 & 0.67 & 0.63 & 0.62 & 0.62 & 0.62 & \begin{tabular}{|l|}
0.67 \\
\end{tabular} & 0.71 & 0.67 & \begin{tabular}{|l|}
0.71 \\
\end{tabular} & 0.71 & \begin{tabular}{|l|}
0.67 \\
\end{tabular} & 0.71 & 0.71 & \begin{tabular}{|l|}
0.71 \\
\end{tabular} & \begin{tabular}{|l|}
0.91 \\
\end{tabular} & \begin{tabular}{|l|}
0.67 \\
\end{tabular} & \begin{tabular}{|l|}
0.71 \\
\end{tabular} & - & & & & & \\
\hline 20 & 0.71 & 0.71 & 0.67 & 0.67 & 0.67 & 0.67 & \begin{tabular}{|l|}
0.71 \\
\end{tabular} & 0.77 & 0.75 & \begin{tabular}{|l|}
0.77 \\
\end{tabular} & 0.77 & \begin{tabular}{|l|}
0.73 \\
\end{tabular} & 0.77 & 0.77 & \begin{tabular}{|l|}
0.77 \\
\end{tabular} & \begin{tabular}{|l|}
1 \\
\end{tabular} & \begin{tabular}{|l|}
0.75 \\
\end{tabular} & \begin{tabular}{|l|}
0.63 \\
\end{tabular} & \begin{tabular}{|l|}
0.91 \\
\end{tabular} & - & & & & \\
\hline 21 & 0.82 & 0.82 & 0.78 & 0.67 & 0.67 & 0.67 & \begin{tabular}{|l|}
0.71 \\
\end{tabular} & \begin{tabular}{|c|}
0.75 \\
\end{tabular} & 0.55 & \begin{tabular}{|l|}
0.75 \\
\end{tabular} & 0.75 & \begin{tabular}{|l|}
0.71 \\
\end{tabular} & 0.75 & 0.75 & \begin{tabular}{|l|l|}
0.75 \\
\end{tabular} & \begin{tabular}{|l|}
0.77 \\
\end{tabular} & \begin{tabular}{|l|}
0.55 \\
\end{tabular} & \begin{tabular}{|l|}
0.84 \\
\end{tabular} & 0.86 & \begin{tabular}{|l|}
0.77 \\
\end{tabular} & - & & & \\
\hline 22 & 0.5 & 0.5 & 0.46 & 0.4 & 0.4 & 0.4 & \begin{tabular}{|l|}
0.5 \\
\end{tabular} & \begin{tabular}{|l|}
0.55 \\
\end{tabular} & 1 & \begin{tabular}{|l|}
0.55 \\
\end{tabular} & 0.55 & \begin{tabular}{|l|}
0.44 \\
\end{tabular} & 0.55 & 0.55 & \begin{tabular}{|l|} 
\\
\end{tabular} & \begin{tabular}{|l|}
0.75 \\
\end{tabular} & \begin{tabular}{|l|}
1 \\
\end{tabular} & \begin{tabular}{|l|}
0.43 \\
\end{tabular} & \begin{tabular}{|l|}
0.67 \\
\end{tabular} & \begin{tabular}{|l|}
0.75 \\
\end{tabular} & 0.55 & - & & \\
\hline 23 & 0.88 & 0.88 & 0.82 & 0.86 & 0.86 & 0.86 & \begin{tabular}{|l|}
0.88 \\
\end{tabular} & \begin{tabular}{|l|}
0.93 \\
\end{tabular} & 0.6 & 0.93 & 0.93 & \begin{tabular}{|l|}
0.92 \\
\end{tabular} & 0.93 & 0.93 & \begin{tabular}{|l|}
0.93 \\
\end{tabular} & \begin{tabular}{|l|}
0.83 \\
\end{tabular} & 0.6 & \begin{tabular}{|l|}
0.78 \\
\end{tabular} & \begin{tabular}{|l|l|} 
\\
\end{tabular} & \begin{tabular}{|l|}
0.83 \\
\end{tabular} & 0.8 & 0.6 & - & \\
\hline 24 & 0.88 & 0.88 & 0.82 & 0.86 & 0.86 & 0.86 & 0.88 & \begin{tabular}{|l|}
0.93 \\
\end{tabular} & 0.6 & \begin{tabular}{|l|}
0.93 \\
\end{tabular} & 0.93 & 0.92 & 0.93 & 0.93 & \begin{tabular}{|l|}
0.93 \\
\end{tabular} & \begin{tabular}{|l|}
0.83 \\
\end{tabular} & \begin{tabular}{|l|}
0.6 \\
\end{tabular} & \begin{tabular}{|l|}
0.78 \\
\end{tabular} & 0.77 & 0.83 & \begin{tabular}{|l|}
0.8 \\
\end{tabular} & 0.6 & 1 & \\
\hline
\end{tabular}

Furthermore, UPGMA grouping reveals that the sea buckthorn germplasm that we have studied can be divided into two distinct clusters (Figure 3). The first cluster was larger and comprised of 17 accessions $(1,2,3,18,4,5,6$, $8,10,11,13,14,15,7,12,23,24)$. The second cluster was smaller comprising of 7 accessions $(9,16,17,19,20,21$, and 22). The estimated genetic distance between these two clusters is 0.14 . The first cluster contains eight subgroups. The first subgroup consists of two accessions wild and cultivated ( 1 and 2), which were the two most closely related accessions. This means that wild accession could be cultivated in Kharkhorin. The second subgroup includes 1, 2, 3, with 1 and 3 being geographically close. Also, 4, 5, 6 grouped in same subgroup, which were closely related and three of them have same geographical origin, respectively Khar
But, Zavkhan aimag, Durvuljin Soum. 8, 10, $11,13,14,15$ accessions make another subgroup and are closely related. Next subgroup includes three accessions $(12,23,24)$, two of them are from the same geographical area, and one of them is geographically nearby. Some studies suggest that genetic diversity within populations can vary due to altitudinal gradients [21].

The second cluster is grouped into four subgroups. First subgroup consists of closely related two accessions (16 and 20), with these two 19 is added, making the next subgroup. Interestingly, accessions 9, 17, 22 showed close relatedness, which are growing in different geographical areas. This indicates to the possibility that they could be genetically similar. Accession 21 showed the highest genetic distance from other accessions. 


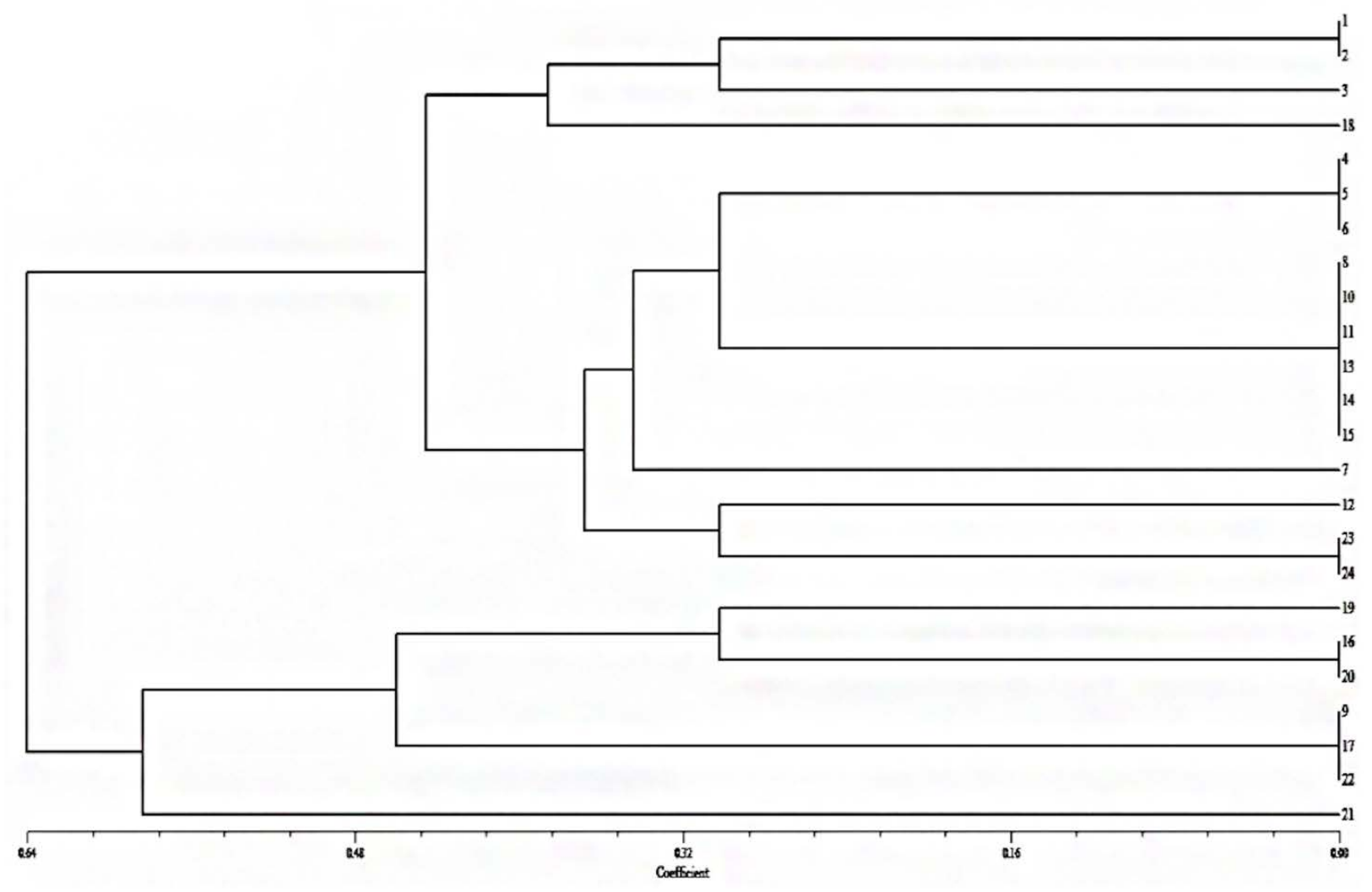

Figure 3. UPGMA dendrogram estimating the genetic distance among 24 different sea buckthorn populations from Mongolia based on RAPD markers

To date, there are limited studies on the genetic relationship and diversity of sea buckthorn of Mongolia. Our result demonstrates the utility of morphological and RAPD-PCR markers for detecting genetic relationship between the accessions of $\mathrm{H}$.

\section{CONCLUSIONS}

On the basis of findings of the present study, it can be concluded that genetic variability in the studied accessions of $H$. rhamnoides L. is high, the accessions of which were collected from different geographical regions. Moreover, selected sets of RAPD markers ensured high level of polymorphism and further can be applied in different $H$. rhamnoides L. subspecies.

Our results suggest that RAPD markers, which were used in our research, can also be applied to access the genetic variability of rhamnoides growing in different sites in Mongolia. The uniqueness of certain bands indicates that a RAPD analysis approach of $H$. rhamnoides is well suited. Resulting information can be used as guidelines for improved germplasm collection and breeding.

selected accessions of $H$. rhamnoides L.. Thus, above results can be the basis for future research to understand genetic variability of Mongolian $H$. rhamnoides L..

Our results suggest that RAPD markers could be used for more precise evaluation of genetic diversity and internal relatedness of sea buckthorn plant material.

Acknowledgements. The work reported in this paper was supported and funded by TA8960 MON: Supporting Value Chain Project, Agriculture and Rural Development Project. 


\section{REFERENCES}

1. A. Rousi, "The genus Hippophae L., a taxonomic study,” Ann. Bot. Fenn, vol. 8, pp. 177-227, 1971.

2. C. Ruan and D. Li, "Community characteristics of Hippophae rhamnoides forest and water and nutrient condition of the woodland in Loess hilly region,” J. Appl. Ecol., vol. 13, No. 9, pp. 1061-1064, 2002.

3. U. Swenson and I. V. Bartish, "Taxonomic synopsis of Hippophae (Elaeagnaceae),” Nord. J. Bot., vol. 22, no. 3, pp. 369-374, 2002.

4. I. V. Bartish, J. W. Kadereit, and H. P. Comes, "Late Quaternary history of Hippophaë rhamnoides L. (Elaeagnaceae) inferred from chalcone synthase intron (Chsi) sequences and chloroplast DNA variation," Mol. Ecol., vol. 15, no. 13, pp. 4065-4083, 2006.

5. I. V. Bartish, N. Jeppsson, and H. Nybom, "Population genetic structure in the dioecious pioneer plant species Hippophae rhamnoides investigated by random amplified polymorphic DNA (RAPD) markers,” Mol. Ecol., vol. 8, no. 5, pp. 791-802, 1999.

6. A. Lecoent, E. Vandecandelaere, and J.-J. Cadilhon, "Quality linked to geographical origin and geographical indications: lessons learned from six case studies in Asia,” RAP Publ., vol. 4, pp. 85-112, 2010.

7. P. B.Durst, W. Ulrich, and M. Kashio, "Non-Wood Forest Products in Asia," RAPA Publ., pp. 1-170, 1994.

8. L. Rongsen, "SEBUCKTHORN A Multipurpose plant species for fraglle mountains,” Int. Cent. Integr. Mt. Dev. Kathmandu, Nepal, vol. 20th ed, pp. 18-20, 1992.

9. S. Saggu, H. M. Divekar, V. Gupta, R. C. Sawhney, P. K. Banerjee, and R. Kumar, "Adaptogenic and safety evaluation of seabuckthorn (Hippophae rhamnoides) leaf extract: A dose dependent study," Food Chem.
Toxicol., vol. 45, no. 4, pp. 609-617, 2007.

10. N. K. Upadhyay, R. Kumar, M. S. Siddiqui, and A. Gupta, "Mechanism of wound-healing activity of hippophae rhamnoides L. leaf extract in experimental burns," Evidence-based Complement. Altern. Med., vol. 2011, 2011.

11. J. Fan, X. Ding, and W. Gu, "Radicalscavenging proanthocyanidins from sea buckthorn seed," Food Chem., vol. 102, no. 1, pp. 168-177, 2007.

12. H. Abid, A. Hussain, and S. Ali, "Physicochemical characteristics and fatty acid composition of seabuckthorn (Hippophae rhamnodes L) oil,” Journal- Chem. Soc. Pakistan, vol. 29, no. 3, pp. 256-259, 2007.

13. R. Ren et al., "The bioactive components as well as the nutritional and health effects of sea buckthorn," RSC Adv., vol. 10, no. 73, pp. 4465444671, 2020.

14. A. Grover and P. C. Sharma, "Development and use of molecular markers: Past and present," Crit. Rev. Biotechnol., vol. 36, no. 2, pp. 290302, 2016.

15. H. A. Persson and H. Nybom, "Genetic sex determination and RAPD marker segregation in the dioecious species sea buckthorn (Hippophae rhamnoides L.),” Hereditas, vol. 129, no. 1, pp. 4551, 1998.

16. I. V. Bartish, N. Jeppsson, G. I. Bartish, R. Lu, and H. Nybom, "Inter- and intraspecific genetic variation in Hippophae (Elaeagnaceae) investigated by RAPD markers,” Plant Syst. Evol., vol. 225, no. 1-4, pp. 85101, 2000.

17. C. Ruan, P. Qin, J. Zheng, and Z. He, "Genetic relationships among some cultivars of sea buckthorn from China, Russia and Mongolia based on RAPD analysis," Sci. Hortic. (Amsterdam)., vol. 101, no. 4, pp. 417-426, 2004. 
18. C. S. Kim, C. H. Lee, J. S. Shin, Y. S. Chung, and N. I. Hyung, “A simple and rapid method for isolation of high quality genomic DNA from fruit trees and conifers using PVP," Nucleic Acids Res., vol. 25, no. 5, pp. 10851086, 1996.

19. N. Jeppsson, I. V Bartish, and H. A. Persson, "DNA analysis as a tool in sea buckthorn breeding," Perspect. new Crop. new uses, pp. 338-341, 1999.
20. G. I. Bartish, N. Jeppsson, I. V. Bartish, and H. Nybom, "Assessment of genetic diversity using RAPD analysis in a germplasm collection of sea buckthorn,” Agric. Food Sci. Finl., vol. 9, no. 4, pp. 279-289, 2000.

21. T. Ohsawa and Y. Ide, "Global patterns of genetic variation in plant species along vertical and horizontal gradients on mountains," Glob. Ecol. Biogeogr., vol. 17, no. 2, pp. 152-163, 2008. 